\title{
The gender perspective for a changing city. Time, Space and Covid in Milan
}

Prof. Francesca Zajczyk, Ph.D

University of Milan-Bicocca, Italy

\section{Abstract}

The city has become a space of diversity. To be sustainable, inclusive and less unequal, urban policy and policies must therefore take these differences into account.

In this moving film, the female component represents a fundamental aspect. For a heavy cultural question, in Italy there has been a delay in society with respect to the idea of equal opportunities between men and women.

Italy remains far from the watchword - mainstreaming - which Europe, on the other hand, has begun to develop and disseminate. And it is a European document that for the first time introduces the theme of the "right to the city for women".

There is certainly no shortage of innovative cases also promoted by female figures in Italian local administrations. In practice, however, a systematic overview is lacking.

Apart from the issue of sustainable mobility, temporal policies are particularly important for a gender sensitive territorial planning. The interesting and innovative aspect is the transversality of the temporal dimension, both in the lives of individuals and in the social organization of urban space.

The lockdown canceled the diversification of the times of daily life and the use of urban space: "time" considered a certain fact, never questioned, has become a precious, quality asset; through new rhythms for a new urban livability and mostly for a better life of women.

For this to happen, however, the city must change its skin, it must change its thinking and above all its rhythms. And this is precisely the perspective recalled in a document drawn up by the Municipality of Milan: "Milan 2020 - Adaptation strategy" (Municipality of Milan, 2020). Therefore, a new Territorial Schedule Plan, whose specificity is the transversality of the temporal dimension. A new city management tool through the organization of time, from timetables to accessibility with particolar attention to the prospect of a "city 15 minutes away".

Promoting women's well-being satisfies collective and community interests and improves the quality of all: women and men.

Keywords: gender; city; times; Covid19; Milan; urban space. 


\section{Introduction}

The city has become a space of diversity. To be sustainable, inclusive and less unequal, urban policy and policies must therefore take these differences into account (Secchi 2014) $)^{1}$.

It is in the city that demographic differences, the different ways of having a family and the different lifestyles, work and relationships are manifested and combined.

Cities - and we are speaking above all for our country - which have an age pyramid that is difficult to assimilate to the classic geometric design of the triangle (or rhombus) but almost tending to inversion with a part that widens compared to a base that tends dangerously shrink: a city of old people and old people with few children.

But also cities that photograph many ways of being together: a growing number of lonely people (also in this case elderly, but - especially in the larger cities - also young people, increasingly mobile in their relationship with work); or couples, without children of both young and old. More and more secularized cities, in which the difficulties in shared relationships and projects - together with an increased autonomy of women - lead to the constant increase of separations and therefore single women, often with small children, but also families of variable dimensions born from new ways to start a family, not to mention the types of families and housing shares of immigrant populations. Furthermore, despite their growing presence on the labor market (regardless of the quality of the job), women in our country continue to occupy a very high number of hours in domestic work and for the family.

In this moving film, the female component represents a fundamental aspect: for overall number, but also for generational differences, family status, employment, origin, level of socio-economic well-being. All conditions that determine and favor very diversified daily behaviors, lifestyles and space-time use of the city.

In other words, although all this is now mostly known to administrators and politicians, the city is interpreted in a "neutral" way and consequently urban policies, such as those of mobility and safety, the related interventions and proposed actions are almost never gender sensitive. Most of the time, at least in Italy, urban policies are aimed at a population as "unicum". In fact, neither the differences between women and men nor the different needs of the population with respect to age are considered.

To promote a good and better quality of life for everyone, citizens and townspeople, it is necessary to make the organization of the city more efficient, from the management and accessibility of the many types of services to the increasingly multifunctional management and use of public spaces. Definitely, different urban policies need to be

${ }^{1}$ Secchi B., The city of the rich and the city of the poor, Laterza, Rome, 2014 
rethought. And to do this, it is essential to transfer knowledge and information that have been acquired over time through studies and research into the construction of policies and city governance.

\section{From the unaware scandal to the conscious one ${ }^{2}$}

In Italy there has been a delay in society with respect to the idea of equal opportunities between men and women. A heavy cultural question that refers to the distinctive characteristics of the country's history, which is evident in the persistent limited presence of women in the labor market and in career paths ${ }^{3}$. This is also demonstrated by the historical absence of mechanisms for promoting women's participation in public life, which is only now beginning to register some changes, but also by the "style" of politics itself, meaning the dynamics, rituals and modalities of management of power which, in our country, retain a decisive, as well as transversal, masculine imprint.

The second element that must be emphasized is the one most deeply connected to the life and roles of Italian women: life and roles that determine self-ideas, needs, desires and ambitions. Italy is the country where there is still a greater disparity in the sharing of domestic and care jobs, which 77 per cent weigh on female shoulders: in the last 20 years, to signify how slow change is, the temporal balance has seen the men devote only about 20 more minutes a day to these activities (Istat, 2010); this percentage then drops to about 11 more minutes per day by employed men (Istat, 2011). It is clear that this judgment translates into varied attitudes with different levels of awareness of the role of stereotypes in the culture of the country.

The intersection of these two elements makes still current, in our opinion, the diagnosis made explicit by some historians of an incomplete citizenship for Italian women who carry many reasons: some are constitutive, linked to the creation of the modern concept of citizenship in liberal regimes, drawn on a single subject that you want neutral, but which is the adult male. Others, instead, which concern, more specifically, the cultural context and the path of the Italians on the path of rights which, starting with the right to vote acquired only in 1945, is still to be done. In fact, 1945 saw women as minors by legal status, and this, as Anna Rossi-Doria argues, made their citizenship weak (Rossi Doria, 1996). In addition to the purely masculine hostility, the strongest prejudice refers to the perception of women as bearers of interests that concern only their sex and not all individuals, as is naturally assumed for men:

However, there is a further element that must be recognized and on which the same women are comparing themselves. The political participation of women in Italy has

\footnotetext{
${ }^{2}$ Sarlo A., Zajczyk F., Where the heart of women in Italy beats, Laterza, Rome, 2012

${ }^{3}$ Even if the Golfo-Mosca (Lella Golfo\&Alessia Mosca) law on "pink quotas" (Law 120/2011) is achieving positive and fast results (about 30\% starting from $5 \%$ ) of women on the boards of directors of listed companies.
} 
also been hampered by the existence of implicitly conflicting visions which have seen on the one hand women who have pursued the path of equal opportunities (very fruitful in Northern European democracies) and on the other those who, on the based on other feminist theories, they have criticized the very foundation of the idea of citizenship, practicing an extraneousness and/or self-exclusion from institutional politics. The critique of theconcept of citizenship has concerned and concerns the false universality of the subject on which it was drawn, since institutions, as we have already said, were originally built to be inhabited only by men.

It is in this context that fits what Reyneri ${ }^{4}$ has defined as the true revolution of the last century: that is, the massive entry into the labor market of young Italians starting from the early 1970s. The theme of productive work with respect to family and care work soon became a central element of women's debate in the political and trade union world, so much so that - thanks to Laura Balbo in $1978^{5}$ - the term "double presence" was coined, evocative of the growing growing difficulty of managing women's daily life.

In a social context that has always considered women in their main role as mothers and housewives, the issue of rights becomes central: certain of subjective rights (divorce and abortion), on the one hand; but also on the other hand, the rights to welfare and to a better condition and quality of life: maternity protection for female workers and personal services (nursery schools and kindergartens in the first place, but also education, health care $)^{6}$. Fundamental changes that affect not only women's lives but that deeply mark the transition from an "ancient" society to one that sees more modern paths in which women begin to occupy a public social space, coming out of the closed - not only material - of the home.

All this, however, takes place without addressing the underlying theme of a cultural gender gap which, in fact, leaves gender identities unaltered.

\section{Gender Urban Development: the European push}

In 1997, with the assumption of the principle of mainstreaming and empowerment in the Treaty of Amsterdam, a path began putying at the center the integration of equality between men and women in all Community and national policies and requiring the adoption of a perspective of gender by all actors in the political process in every sector of activity. Principles made more explicit and meaningful in the "Charter for Women", a political document adopted on 5 March 2010 by the Commission for the period

\footnotetext{
${ }^{4}$ Emilio Reyneri, Sociology of the labor market, II Mulino, Bologna, 2011.

${ }^{5}$ Laura Balbo, Marina Bianchi, Lorenza Zanuso, Elisabeth Wilson, "Double presence and the female labor market: a research on the condition of women in advanced capitalist societies", in Investigation no. 32, 1978.

${ }^{6}$ Cristina Renzoni, Welfare for women. Project associations and public services in the years of the miracle, in Territory, Fascicolo 69, 2014, pp. 48-53.
} 
2010 - 2015, to enhance the promotion of gender equality between men and women in all fields of action of the 'EU, also coinciding with the 15th anniversary of the Beijing Conference and the 30th anniversary of the UN Convention on the Elimination of All Types of Discrimination Against Women.

The Women's Charter proposes five fields of action to guide European policies and to encourage action beyond its borders to support the development of democratic societies. These include the issue of economic independence to be achieved in order to combat discrimination, stereotypes and segregation in the labor market, in education, and in the social sector. And again, to encourage the full realization of the potential of women and the full use of their skills, their participation in decision-making processes and to occupy positions of power both in the public and private sectors. The Charter reaffirms the Commission's attention to respect for the dignity and integrity of women, and the commitment against gender-based violence.

Without detracting from the relevance of this document, the 1994-95 Research-Action project, which goes by the name of "European Charter for Women in the City", drawn up with the support of the Commission, from our point of view deserves particular attention. European contribution to the debate on citizenship and the city in view of the World Conference of Women in September 1995 in Beijing and subsequent international meetings planned on the theme of the City.

It is the first time that the theme of the city as a human settlement is introduced in official documents and refers to the Proposal for a new model of interpretation of the city "at the basis of a" Right to the city for women", for an equal democracy to improve everyone's life.

The words that illustrate the objectives and philosophy of the Charter are extraordinarily current.

The proposal for a Charter for women in the city aims to elaborate a new philosophy of urban planning, capable of constructively fostering a true democratic debate that integrates the needs and different expectations of citizens. The revitalization efforts of our cities must converge towards the emergence of other political and economic priorities towards greater harmonization on the social level. The challenge is the reconstruction of places, places and the bonds of social cohesion that allow equal opportunities between men and women both in the urban and rural environment.

This Charter essentially aims to promote a more emancipated society, freed from the pressing stereotypes that are holding back any development favorable to women in the field of urban services, habitat, safety and mobility. 
It is therefore necessary to think and remodel the city through the eyes of women in order to bring another dimension and new balances ${ }^{7}$.

All this taking into account, as a Preamble of the Charter, women can still play a catalytic role in the process of change and improvement. of everyone's way of life, even if their interest does not (yet) manifest itself towards the territory and space

The five main areas of intervention identified are equally current:

- Urban planning and the territory

- Mobility

- Urban security

- Housing

- Strategies

Twelve points in the Declaration explain the philosophy behind the document, both from the point of view of the analysis and with respect to the strategies to be adopted ${ }^{8}$.

The diffusion of the Charter, both in Europe and in international organizations, favors the establishment of women's networks that begin to activate a holistic approach to the creation of "infrastructures for everyday life", focusing on the reflection on the role of women for a more just city and equitable, which recognizes the full right of citizenship to the female population.

The gender perspective, therefore, becomes a lens through which to respond first of all to needs, different needs that coexist in the urban dimension, without however being really considered by the "neutral" approach which, in fact, tends (or risks) to produce new and wider inequalities.

And it is in this context that issues such as housing, the redevelopment of neighborhoods, the organization and management of public spaces (starting from safety), mobility accessible to all begin to fit the agenda of urban planning in many cities. with a design approach that take into account to responding to needs and requirements coming from different spatial-temporal lifestyles, depending on gender and age.

\footnotetext{
${ }^{7}$ European Charter for Women in the City, at http://www.habiter-autrement.org/22_sex/17_gender.htm

${ }^{8}$ WOMEN IN THE CITY AND ACTIVE CITIZENSHIP

WOMEN IN THE CITY AND DECISION-MAKING AND EQUAL DEMOCRACY

WOMEN IN THE CITY AND EQUAL OPPORTUNITY

WOMEN IN THE CITY AND PARTICIPATION

WOMEN IN THE CITY AND EVERYDAY LIFE.

WOMEN IN THE CITY AND DURABLE DEVELOPMENT

WOMEN IN THE CITY AND SECURITY AND MOBILITY

WOMEN IN THE CITY AND THE RIGHT TO ACCOMMODATION AND LIVING

WOMEN IN THE CITY AND THE SIZE OF GENDER.

WOMEN IN THE CITY AND TEACHING AND LOCAL EXPERIMENTATION.

WOMEN IN THE CITY AND THE ROLE OF THE MEDIA AND THE TRANSMISSION OF EXPERIENCES

WOMEN IN THE CITY AND THE NETWORKS
} 


\section{The Italian experience: a practice that does not take root}

In Italy, the thought of "difference" in terms of urban planning and gender policies since the 1970s has produced research, documents, maps. Has experimented with practices in many realities, generating networks in the academic and associative fields. In particular, the role and the push of the UDI (Italian Women Union) is significant for the introduction of minimum standards for equipment in the national urban planning legislation but also for the drafting of the Charter of ideas for urban and territorial quality, promoted by Ministry for Equal Opportunities.

However, attention to gender in the construction of policies is rather sporadic, certainly not part of a coherent and progressive process. Projects and actions are activated, but these are drives born of scholars who, alone or in associations, experiment with the introduction of a gender perspective in individual design processes, placing the complexity of everyday life at the center of urban events.

There is certainly no shortage of innovative cases also promoted by female figures in local administrations. In practice, however, the passage that studies and research would have hoped for with a widespread and rooted practice in the administrations remains lacking.

For (sustainable) mobility for all

When addressing the issue of territorial planning, one cannot fail to speak of mobility and accessibility. And today more than ever it cannot be done without a gender sensitive vision

Mobility represents, together with the birth and spread of new information technologies, one of the peculiar features of contemporary social life. This is shown by the results of the statistics, which identify mobility as the activity to which subjects devote increasing shares of their time, but remember it, more simply, our agendas that increasingly resemble maps of activities scattered over time and in daily space. The surveys agree that, compared to the past, in contemporary societies there are more mobile people and more and more are also those previously characterized by a lower propensity to move, such as the elderly and especially women (Urry, J., 2005; PriyaUteng, T., Cresswell, T. (eds) 2008; Istat, 2014). Particularly when employed, women are not only mobile but also have increasingly multimodal, fragmentary and non-systematic movement styles.

The analysis of the consequences of increased mobility and its greater frequency on access to urban services is the subject of attention by a growing share of studies carried out, in particular, at the international level. These are inscribed both in the field of gender studies and in the fields of research relating to transport and mobility. 
Many of these argue that there is not always a direct relationship between mobility and access to services and that it is above all women who show mobility styles that lead to low levels of access to urban places and services and, consequently, to new forms of inequality. gender; moreover, many of the differences in mobility are determined by the fact that women tend to carry out more diversified activities than men. ${ }^{9}$

In our country these differences are not considered and this has significant implications: the planning of transport services, and transport in general, is still entirely designed on systematic mobility that better responds to the mobility needs of the male population. Collective transport services are designed on the needs of home-work and home-school mobility, both as a network of services and as frequencies: consequently, they are less frequent in the hours when they are most used by women and offer fewer direct services from origin to destination. Even the fare structure is to the disadvantage of this less systematic mobility: in general, season tickets rarely cover erratic journeys (if not at very high prices) and therefore it is necessary to use the more expensive full tickets, despite the fact that women are the main users of the means. public (as shown by the survey conducted in Scotland on mobility cited in a study by He, Raeside, Chen and Mc Quaid but also by the results of the Italian surveys, Isfort 2013).

In fact, there are no adequate sidewalks to reach the means; buses, trams, trains and subways are not designed to facilitate getting on and off with packages, strollers, children by the hand. And to return to the issue of safety, the changes in working hours and lifestyles mean that women move more and more even in the evening or at night, the same when there are fewer services. But apart from a few exceptions, whether they use private vehicles or collective transport, their safety meets not enough attention: apart from well-lit stops, parking in more visible areas, pink taxis... why not also carriages dedicated only to women?

In short, taking advantage of the tools of the Urban Traffic Plan (PUT) and the Urban Mobility Plan (PUM) it is now necessary to begin to introduce a gender vision also in transport planning and policy, modifying a mobility system that tends to aggravate the already significant weight of the double role. And leveraging gender diversity in urban planning tools could be a concrete way to promote more sustainable mobility for all.

\section{Time policies and accessibility of services}

From this point of view, the only developed real experience is the experience linked to the politics of the times; not only limited experiments, but also policies with a gender perspective, which gave birth to a real law. A particularly exceptional case because

\footnotetext{
${ }_{9}^{9}$ The studies of the Transport and gender area of the World bank are particularly interesting (http://www4.worldbank.org/ afr/ssatp/Resources/HTML/Gender-RG/index.html); furthemore, the studies of the OECD and the International transport forum http://www.internationaltransportforum.org/Pub/new.html; the UK Department of Transport investigations; the articles published in the issue of Research and Transportation Economics Journal, totally dedicated to the topic of Transport and Gender.
} 
Italy has been the first country in Europe to elaborate a holistic vision of individual and family daily life in relation to urban organization.

At the basis of these policies is the idea that the public administration can actively intervene to allow citizens, but above all to citizens, a more balanced use of their personal time, thus improving the allocation of this resource also from a point of social view.

The term indicates that set of actions aimed at improving the quality of life of citizens and urban quality, through the design and implementation of interventions on the times and schedules of the city: for a better balance of family times, working times and time itself as well as for a better spatial and temporal use of the city.

Law 53/2000 provided, among other things, that within six months of its entry into force, the Regions would define specific rules for the coordination by the Municipalities of the opening hours of shops, public services and peripheral offices of the administrations. In particular, it was prescribed that Municipalities with a population greater than 30,000 inhabitants were required to identify sombody responsible for competence in the matter of times and schedules and the responsibility of drawing up the Territorial Plan of Timetables: a document aimed at harmonizing the time schedules in cities taking into account "the effects on traffic, pollution and the quality of city life of public and private working times, public and private service entriyand exit times, peripheral offices of public administrations, commercial activities ".

Through the Times Regional Laws subsequently promulgated, important issues, such as the governance of time, time as a resource and time as a project, have gender perspective at main criterion.

It should be remembered that topics and contents of these legislation actually arose around the 1980s on the wave of a strong push from the female component of the trade union movement which collects some elaborations from the world of research and which consequently produces a bill presented from the women of the Comunist Party (PCl) entitled "Women Change Times".

The focus was on women who, entered the labor market in large numbers in the seventies, in the double role of workers and family managers, were affected not only by an inequitable Diseguale division of social roles, but also by a disharmonious organization of city timetables.

The interesting and innovative aspect that clearly emerges in this phase is the transversality of the temporal dimension, both in the lives of individuals and in the social organization of urban space. there are in fact many areas in which time can 
enter as a criterion of choice and an asset to "preserve": From roads to commerce, from health to education, from work to urban safety.

Temporal policies therefore have a clear pervasive vocation. From time to time they should affect the urban planning choices present in the Territory Governance Plan; guide the regulation and location of commercial businesses; push towards a different organization of services open to the public (offices, schools, hospitals); influence local public transport decisions; promote greater flexibility in working times. For this reason, adopting temporal policies, means first of all radically changing the internal decision-making dynamics of public bodies and rethinking the traditional methods adopted to read the needs of the territory. A complex challenge for administrations, used to analyzing problems and designing interventions, always responding to specific and partial requests.

To balance is not a problem that concerns only the private sphere, but also the collective, public, and consequently the political one. The need arises to rethink a reorganization of the city through the organization of time, from timetables to accessibility.

With respect to this reference framework, the regional laws promulgated after the law $53 / 2000$ call the Municipalities to develop their experimentation projects based on the following main thematic areas:

a) Sustainable mobility of people and goods, to manage traffic and the quality of the environment also through alternative forms of mobility;

b) Accessibility and temporal usability of public and private services, promoting coordination between timetables and location of services and favoring the plurality of the offer;

c) Regeneration of urban spaces to improve social networks and promotion of mobility paths for different age groups;

d) Coordination of timetables and services with the system of working times, promotion of equal opportunities between men and women to favor the balance between family and professional responsibilities and a better distribution of these responsibility within the family;

e) Use of time for mutual solidarity and interest by promoting in particular the establishment of the so-called Time-Banks associations.

It is therefore evident that reasoning about time and promoting practices about time produces actions that go towards improving the quality of life and relationships for all according to a perspective of gender, generations and different citizens needs; and not just women. 


\section{Covid19 Pandemic and city life}

Covid19, and above all the first measure taken to counter it, have produced the image of empty, motionless and silent cities, in which Time has stopped and life itself has stopped.

The lockdown canceled the diversification of the times of daily life and the use of urban space: it became a time forcibly private, but in many cases fragmented within the walls of the house. A time that has accentuated isolation and a sense of loneliness for many lonely people, especially the elderly and mostly elderly women; deprived children and young people of the opportunity to enjoy the right to education and the presence of social relations; finally, it has deprived adults of the possibility - wanted or not - of being able to continue working by going collectively to the workplace.

And if the external image of the cities (do we remember the first videos of the city of Wuhan?) has most often returned a scenario of estrangement, desolation and almost the end of the world, it is actually about the times of the people locked up in the houses that the greatest repercussions and criticalities were produced. Many critical issues and all the more difficult to manage, the smaller the closed environment was and with limited spaces. Spaces within which one had to be able to carve out time for oneself, but live with children deprived of their leisure time and play outdoors. But also spaces and times to dedicate to remote learning and work from home. And if we do not want to deal here with the issue of remote learning, which refers to issues that do not only concern the temporal aspect, we cannot fail to mention the repercussions that closed schools have determined on the management of time by women. This situation often forced women to extend the time of remote work: it resulted in a difficult balancing between the time of childcare, perhaps little ones; time to help older ones and time of duty dictated by work, which, despite being at in remote, remains strongly controlled by the responsible boss, perhaps in a situation of obligatory necessity given by sharing some kind of technological device: a rather stressful balancing act and balancing act if you add to this the persistent and unequal division between male and female roles in domestic activities (Istat, 2014).

\section{For a new city image: the case of Milan}

As we reccled above, it is worth remembering that "politics of the times" were already spoken of around the nineties.

It was a phase full of administrative experiments and innovations in which Milan represented the leading city, having been the first city in Italy and in Europe to draw up a plan of times and timetables, still a reference point today, which launched the first slogans on the relationship between times and cities and which, utopian then, slowly, but also increasingly quickly, became reality. We recall two, particularly current: "a city 
always open (24 hours a day)", which presupposed the liberalization of trading hours, and "move the cards and not the people", through an increasingly pervasive use of technology.

And this is what Milan has/had become: a frenetic, hysterical city, with ever more accelerated rhythms and a high numers of working women. But it is also the city that the need to introduce health defense measures from Covid19 has suddenly and radically put it in crisis. What perhaps, was a simple intuition, has become a necessity. "Time" considered a certain fact, never questioned, has become a precious, quality asset; through new rhythms for a new urban livability and mostly for a better life of women.

For this to happen, however, the city must change its skin, it must change its thinking and above all its rhythms.

And this is precisely the perspective recalled in a document drawn up by the Municipality of Milan, with the evocative title: "Milan 2020 - Adaptation strategy" (Municipality of Milan, 2020). Therefore, a new Territorial Schedule Plan, whose specificity is the transversality of the temporal dimension, both in the lives of men and women, and in the social organization of urban space. A new city management tool through the organization of time, from timetables to accessibility.

We can summarize the temporal re-planning of the city according to three main objectives.

First of all, the dilution of the demand for private and public mobility throughout the 24 hours of the day, which is accompanied by a great boost to cycling and walkability. Secondly, a flexibility and desynchronization of the start and end times of public service activities, especially socio-educational, commercial, and recreational and recreational activities. Finally, the topic of proximity, a space-time concept that presupposes "everything 15 minutes away"; a sort of community-neighborhood in which physical proximity access to public services is guaranteed, first of all, but not only, also favoring their use through digital services.

In conclusion, three guiding objectives, which help to glimpse the vision of the future, a challenge towards the future. But special attention goes to yhe prospect of a "city 15 minutes away".

The city 15 minutes, promoting proximity and a sense of community is particularly favorable to the life of women, of all women who represent a mosaic of today's complexity: young women, often mothers of small children, workers, forced to a difficult reconciliation of times of life, with a life still today especially in Italy characterized by a strong gender imbalance. But also elderly women, more and more numerous in a 
rapidly aging society: women, therefore, who need nearby services, easy to reach, proximity shops, easy and continuous social relationships.

Promoting women's well-being satisfies collective and community interests and improves the quality of all: women and men.

\section{Bibliography}

1. Balbo L., Bianchi M., Zanuso L., Wilson E., (edited by), "Double presence and the female labor market: a research on the condition of women in advanced capitalist societies", in Inquiry n. 32, 1978.

2. Balbo L., Times of life. Studies and proposals to change them, Feltrinelli, Milan 1991.

3. Bassanini G., For the love of the city. Women, participation, project, FrancoAngeli, Milan, 2008.

4. Bimbi F., (edited by), Differences and inequalities. Perspectives for gender studies in Italy, Bologna, II Mulino, 2003.

5. Chriss, James J. "COVID-19 and Social Control." Academicus International Scientific Journal 23 (2021): 21-40.

6. Colleoni, M. -Zajczyk, F., The time of female mobility in the society of widespread urban settlements, in Estranee in the city. At home, in the streets, in the places of study and work, by A. Mazzette (edited by), FrancoAngeli, Milano, pp. 19-32, 2009.

7. Cresswell, T. - Uteng, T. P., GenderedMobilities: Towards a Holistic Understanding, in Gendered Mobilities, edited by T. P. Uteng e T. Cresswell (edited by), Ashgate, Aldershot, pp. 1-14, 2008.

8. Decataldo A., Ruspini E, Gender research, Carocci, Rome, 2013.

9. Droste C., Gender in Mainstreaming Urban Development - Berlin on the path towards becoming a metropolis worth living in for women and men, Berlin Handbook, Senate Department for Urban Development - Office of the Women's Advisory Committee, Editor of the English edition, Berlin, June 2011.

10. Droste, C. E - Zajczyk, F. 2006 The Gender Perspective, in Regenerating Large Housing Estates in Europe, edited by R. Kampen, A. Murie, T. Knorr-Siedow (edited by), University of Utrecht. Utrecht, pp. 151-68, 2006.

11. European Charter for Women in the City: http://www.habiter-autrement. org/22_sex/17_genre.htm

12. Ferrarotti, Franco. "The Estrangement of Youth and the Quest for a different Society." Academicus International Scientific Journal 8.16 (2017): 9-32. 
13. Filippini, N. M., Scattigno, A. (edited by), An unfinished democracy. Women and politics in Italy from the nineteenth century to ours days, Franco Angeli, Milan, 2007.

14. Galeotti, G., History of voting for women in Italy. At the roots of the difficult relationship between women and politics, Biblink, Rome, 2006.

15. Handbook, Senate Department for Urban Development, Berlin, 2011.

16. He, L., Raeside, R., Chen, T., McQuaid, R. W., Population Ageing, Gender and the Transportation System, in «Research in Transportation Economics», 34, pp. 39-47, 2012.

17. ISFORT, The demand for obility of Italians, Year-end Economic Report, audimob - Observatory on the mobility behavior of Italianas, Rome, 2013.

18. Istat (2011), Changes in life times and leisure activities, in Statistics Report, 6 December 2011.

19. Istat, Annual Report 2014, Rome, 2014.

20. Iveson, K. - Fincher, R. "Just Diversity» in the City of Difference, in The New Blackwell Companionto the City, edited by G. Bridge, R. Fincher, K. Iveson, S. Watson, Blackwell Publishing, Oxford, pp. 407-18, 2011.

21. Kail E. and Irschik E., Strategies for Action in Neighborhood Mobility Design in Vienna - Gender Mainstreaming Pilot District Mariahilf, German Journal of Urban Studies Vol. 46 (2007), No. 2I, 2007.

22. Kaufmann, V., Bergman, M.M., Joye, D. Motility: Mobility as Capital, in "International Journal of Urban and Regional Research", n. 28 (4), pp. 745-756, 2004.

23. Melbourne, Public Space Improvement Project - 2013-2014.

24. Municipality of Milan, 2020, Milan 2020 - Adaptation strategy, April 2020, Milan, Italy.

25. Renzoni C., Welfare for women. Project associations and public services in the years of the miracle, in Territory, Fascicolo 69, 2014, pp. 48-53, 2014.

26. Reyneri E., Sociology of the labor market, II Mulino, Bologna, 2011.

27. Rossi-Doria A. Becoming citizens. The vote for women in Italy, Giunti, Florence, 1996.

28. Sarlo A., Zajczyk F., Where the heart of women in Italy beats, Laterza, Rome, 2012.

29. Secchi B., The city of the rich and the city of the poor, Laterza, Rome, 2014.

30. Sineau, M., Women in the sphere of politics: women's rights and democracy, in History of women in the West, edited by G. Duby, M. Perrot, F. Thébaud, v, 2003. 
31. Urry, J. The Complexity Turn, in Theory, Culture \& Society, 22, 5, pp. 114, 2005.

32. Vitali, W. (edited by), An agenda for cities, II Mulino, Bologna, 2014.

33. Walsh, M., Gender in the History of Transportation Services: A Historiographical Perspective, in Business History Rewiev, 81, pp. 545-62, 2007.

34. Zajczyk F., Accessibility and social equity - A study in the metropolitan area of Milan, in MOVE FORUM 2006 Final technical report, pp. 37-56, www.moveforum.net, The time of female mobility in the society of widespread urban settlements (with Colleoni, M.) in Estranee in città. At home, in the streets, in the places of study and work, Mazzette, A. (edited by), Franco Angeli, 2009.

35. Zajczyk F., The gender perspective (with C. Droste), in Regenerating large housing estates in Europe. A guide to better practice, RESTATE, Utrecht University, 2006.

36. Zajczyk F., Life times and hours of the city. Social research and urban governance, Franco Angeli, Milan, 2000.

37. Zajczyk F., Times of life and schedules of the city. Social research and urban government, Franco Angeli, Milan, 2007.

38. Zedda R., Times of the city. Methods for urban analysis, Franco Angeli, Milan, 2009. 